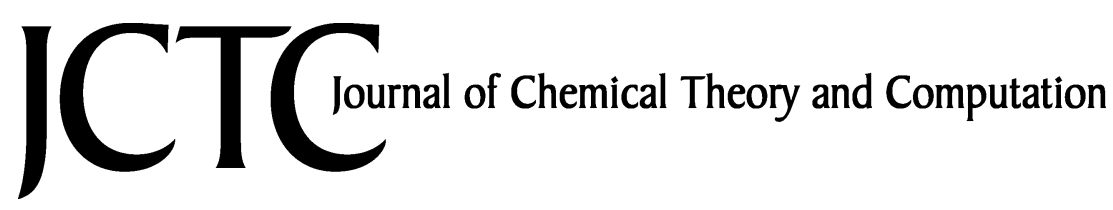

\title{
Activation of Carbon-Hydrogen and Hydrogen-Hydrogen Bonds by Copper-Nitrenes: A Comparison of Density Functional Theory with Single- and Multireference Correlation Consistent Composite Approaches
}

\author{
Sammer M. Tekarli, T. Gavin Williams, and Thomas R. Cundari* \\ Department of Chemistry, Center for Advanced Scientific Computing and Modeling \\ (CASCaM), University of North Texas, Box 305070, Denton, Texas 76203-5070
}

Received May 29, 2009

\begin{abstract}
The kinetics and thermodynamics of copper-mediated nitrene insertion into $\mathrm{C}-\mathrm{H}$ and $\mathrm{H}-\mathrm{H}$ bonds (the former of methane) have been studied using several levels of theory: B3LYP/6-311++G(d,p), B97-1/cc-pVTZ, PBE1KCIS/cc-pVTZ, and ccCA (correlation consistent Composite Approach). The results show no significant difference among the DFT methods. All three DFT methods predict the ground state of the copper-nitrene model complex, $\mathrm{L}^{\prime} \mathrm{Cu}(\mathrm{NH})$, to be a triplet, while single reference ccCA predicts the singlet to be the ground state. The contributions to the total CCCA energy indicate that the singlet state is favored at the MP2/CBS level of theory, while electron correlation beyond this level $(\operatorname{CCSD}(T))$ favors a triplet state, resulting in a close energetic balance between the two states. A multireference ccCA method is applied to the nitrene active species and supports the assignment of a singlet ground state. In general, the largest difference in the model reaction cycles between DFT and ccCA methods is for processes involving radicals and bond dissociation.
\end{abstract}

\section{Introduction}

Carbon-hydrogen bond activation and functionalization are among the most heavily researched endeavors in catalysis, given their importance in the production of useful products from natural gas and petroleum. Development of catalysts for functionalization of carbon-hydrogen bonds (particularly for unactivated aliphatics and aromatics) has been actively pursued by experimentalists and theorists attempting to identify better catalysts. ${ }^{1-6} \mathrm{Ca}-$ talysis of such reactions by late transition metal (TM) complexes has received much recent attention due to their lower electrophilicity and thus greater heteroatom tolerance (versus comparable early TM complexes). ${ }^{7}$ Moreover, such metals are relatively inexpensive in relation to the noble metals.

Phosphines $\left(\mathrm{PR}_{3}\right)$ have long been the ligand of choice for many middle-late TM catalysts. ${ }^{8-14}$ Notable experimental

\footnotetext{
* Corresponding author e-mail: t@unt.edu.
}

work on late $3 \mathrm{~d}$ TM multiply bonded complexes supported by bis-phosphine ligation has been done by the Hillhouse group, who have demonstrated group transfer to a variety of substrates (e.g., olefins and $\mathrm{CO}$ ) using nickel-nitrene, - carbene, and - phosphinidene complexes. ${ }^{8-14}$ Ligands in the $\beta$-diketiminate family have started to augment phosphines in the study of late TM catalysis. ${ }^{15}$ Attention has also focused on $\beta$-diketiminate and related ligands because of their ability to enforce low metal coordination numbers. Also, varying the substituents on the ligating nitrogens, the backbone carbons, linking the $\beta$-diketiminate ring with other moieties to form fused rings, and so forth gives these ligands tunable electronic and steric features. ${ }^{15}$ For example, varying $\beta$-diketiminate substituents has been shown by Shimokawa et al. to produce different coordination geometries (i.e., tetrahedral, distorted tetrahedral, and square planar), different electronic spectra, and electrochemical responses for a series of copper complexes. ${ }^{16}$ In a review on $\beta$-diketiminates, ${ }^{15}$ these ligands are seen to bind strongly to a diverse assortment 
of metals in a wide range of bonding modes and stabilize lower than typical metal oxidation states (e.g., $\mathrm{Fe}(\mathrm{I}), \mathrm{Co}(\mathrm{I})$ or $\mathrm{Ni}(\mathrm{I})$ ).

These features have led to many notable examples of transition metal $\beta$-diketiminate complexes of the late $3 \mathrm{~d}$ metals: $\mathrm{Fe}, \mathrm{Co}, \mathrm{Ni}$, and $\mathrm{Cu}$. For example, a recent report by Holland et al. ${ }^{17}$ investigated the metastable iron(III)-imido complexes that effect hydrogen atom abstraction (HAA) of 1,4-cyclohexadiene. The imido complex becomes active only after the addition of a fourth ligand, 4-tert-butyl-pyridine. Coordination of the fourth ligand to iron is postulated-via a combination of experimental Mossbauer spectroscopy and DFT calculations - to induce a "flip" from a lower to a high spin state. ${ }^{17}$ The synthesis and X-ray crystal structure characterization of a $\beta$-diketiminato $\mathrm{Co}(\mathrm{I})$ arene adduct and its reactivity with dioxygen and organoazides has been reported by Warren et al. ${ }^{18} \mathrm{~A}$ terminal imido Ni(III) complex, also reported by Warren and co-workers, has been shown to effect $\mathrm{C}-\mathrm{H}$ bond activation. ${ }^{19}$

Among late TMs, the coinage metals $\mathrm{Cu}, \mathrm{Ag}$, and $\mathrm{Au}$ have been extensively studied for catalytic nitrene transfer. ${ }^{20-26}$ For example, Dias et al. have reported $\mathrm{Cu}(\mathrm{I})$ and $\mathrm{Ag}(\mathrm{I})$ scorpionate complexes as carbene and nitrene transfer catalysts. ${ }^{24}$ A silver-catalyzed amination of saturated $\mathrm{C}-\mathrm{H}$ bonds (including relatively inert $\mathrm{C}_{\mathrm{sp} 3}-\mathrm{H}$ bonds of cycloalkanes) has also been reported by $\mathrm{He}$ et al. ${ }^{22} \mathrm{~A}$ disilver structure has been identified by the He group as critical in silver-based nitrene transfer. ${ }^{22} \mathrm{He}$ and co-workers also reported $\mathrm{C}-\mathrm{H}$ bond activation at room temperature using gold-catalyzed nitrene insertion. ${ }^{23}$ They found that, for $\mathrm{C}-\mathrm{H}$ bond activation, a nearby aromatic $\mathrm{C}-\mathrm{H}$ bond is needed, presumably to "direct" the activation/insertion event. Copper-scorpionate catalysts (i.e., $\mathrm{Tp}^{\mathrm{Br} 3} \mathrm{Cu}(\mathrm{NCMe})$ ) have been reported by Perez and co-workers to aminate $\mathrm{C}-\mathrm{H}$ bonds. ${ }^{21}$ The complex $\mathrm{Tp}^{\mathrm{Br} 3} \mathrm{Cu}(\mathrm{NCMe})$ catalyzes the amination of $\mathrm{C}-\mathrm{H}$ bonds of cyclohexane and benzene and the primary $\mathrm{C}-\mathrm{H}$ bond of toluene and mesitylene methyl groups using iodonium imide $(\mathrm{PhI}=\mathrm{NT})$ as a nitrene transfer reagent. $^{21}$

Warren and Badiei ${ }^{27}$ synthesized and structurally characterized $\mathrm{Cu}-\beta$-diketiminate-carbene complexes and concluded from density functional theory (DFT) calculations that there is significant $\pi$ bonding between $\mathrm{Cu}$ and the $\mathrm{C}$ of the $\mathrm{CPh}_{2}$ (i.e., carbene). The foregoing suggests the potential for (meta)stable nitrene complexes of $\mathrm{Cu}$. Warren et al. reported that the reaction of $\mathrm{N}_{3} \mathrm{Ar}$ with $\left\{\left[\mathrm{Me}_{3} \mathrm{NN}\right] \mathrm{Cu}\right\}_{2^{-}}$ (toluene) produces a dicopper nitrene $\left\{\left[\mathrm{Me}_{3} \mathrm{NN}\right] \mathrm{Cu}\right\}_{2}(\mu$ $\mathrm{NAr}$ ). Evidence has been obtained that the latter gives rise to a terminal $\mathrm{Cu}$-nitrene through slow dissociation. ${ }^{28}$ Cundari et al. studied complexes of the form ( $\beta$-diketiminate) $\mathrm{Cu}(\mathrm{NPh})$ using DFT, complete active space selfconsistent-field (CASSCF), and hybrid quantum mechanical/ molecular mechanical (QM/MM) methods. CASSCF and $\mathrm{QM} / \mathrm{MM}$ calculations (the QM portion of the latter is of the CASSCF variety) indicate an "open shell" singlet ground state, contrary to prior DFT predictions. ${ }^{29}$ A singlet is synthetically preferable, as this implies (and experimental studies support this contention $)^{30}$ that the copper nitrene will thus undergo amination reactions via concerted $\mathrm{C}-\mathrm{H}$ inser- tion bonds rather than less selective radical reactions one might expect from a triplet active species. ${ }^{29}$ Recent work thus suggests that such complexes can provide a rational basis for engineering novel $\mathrm{C}-\mathrm{H}$ functionalization catalysts capable of activating even the strongest $\mathrm{C}-\mathrm{H}$ bonds. ${ }^{29,30}$

Many computational studies of $\mathrm{C}-\mathrm{H}$ activation, most notably early research by Hoffmann and more recently by Goddard et al., Cundari and co-workers, and Hall et al. ${ }^{31-38}$ have modeled the mechanisms of $\mathrm{C}-\mathrm{H}$ activation. In this work, first-principles modeling of nitrene insertion into $\mathrm{C}-\mathrm{H}$ and $\mathrm{H}-\mathrm{H}$ bonds has been performed. Reactions of a $\beta$-diketiminate $-\mathrm{Cu}-$ nitrene (i.e., $\mathrm{L}^{\prime} \mathrm{Cu}(\mathrm{NH}) ; \mathrm{L}^{\prime}$ is the parent $\beta$-diketiminate anion, $\mathrm{C}_{3} \mathrm{~N}_{2} \mathrm{H}_{5}{ }^{-}$) with $\mathrm{H}_{2}$ and $\mathrm{CH}_{4}$ have been performed in order to understand strong $\left(\mathrm{BDE}_{\mathrm{Me}-\mathrm{H}} \sim 104\right.$ $\mathrm{kcal} \mathrm{mol}^{-1}$ ) bond activation. Also, we seek to probe the impact of changes to the level of theory beyond approaches (i.e., B3LYP and Pople-style basis sets) now commonplace in the literature. Hence, the kinetics and thermodynamics of B3LYP/6-311++G(d,p), B97-1/cc-pVTZ, PBE1KCIS/ccpVTZ, and the correlation consistent Composite Approach $(\mathrm{ccCA})^{39-43}$ are compared. The aforementioned methods have also been used to delineate the singlet $(S=0)$ and triplet $(S=1)$ surfaces for these model catalytic reactions. A multireference ccCA, reported by Wilson and co-workers, is also used to study the nitrene active species.

\section{Computational Methods}

Geometry optimizations of all minima and transition states were performed using the Gaussian 03 suite of programs. ${ }^{44}$ Unless otherwise specified, calculations were performed using the B3LYP hybrid functional in conjunction with the 6-311++G(d,p) where $(\mathrm{d}, \mathrm{p})$ signifies addition of $\mathrm{d}$ - and p-polarization functions to main group elements and hydrogen atoms, respectively. ${ }^{45}$ This basis set adds diffuse spd and $\mathrm{f}$ polarization functions to copper. PBE1KCIS was used in conjunction with the cc-pVTZ basis set. $^{46-54}$ The PBE1KCIS functional was found by Wilson and co-workers to best predict enthalpies of formation for TM complexes and therefore is utilized in this study to provide a base of comparison with the more popular B3LYP functional. ${ }^{45,55-57}$ The B97-1 functional has the lowest mean absolute deviation for calculated versus experimental enthalpies of formation of $3 \mathrm{~d}$ TM-containing molecules in a study by Wilson and co-workers. ${ }^{57}$ Therefore, the B97-1 has also been used in this research. Vibrational frequencies are calculated at all DFT optimized stationary points to confirm them as minima or transition states. Modeling of triplet species with density functional theory employs unrestricted Kohn-Sham methods.

Previous work has shown that the mean absolute deviation for energetics using ccCA is $0.89 \mathrm{kcal} \mathrm{mol}^{-1}$, which is within "chemical accuracy" (i.e., $\pm 1 \mathrm{kcal} \mathrm{mol}^{-1}$ ). ${ }^{39-43}$ Hence, the ccCA approach was employed in this study to compare with results obtained from DFT methods. Classical activation barriers as predicted by $\operatorname{ccCA}^{42}$ were in much better agreement than G3B as compared to very high accuracy computed values obtained from the Truhlar et al. databases. ${ }^{58}$

The ccCA composite method uses the correlation consistent basis sets originally developed by Dunning et al. ${ }^{46}$ The ccCA method has also been shown to achieve "transition 


\section{Scheme 1}

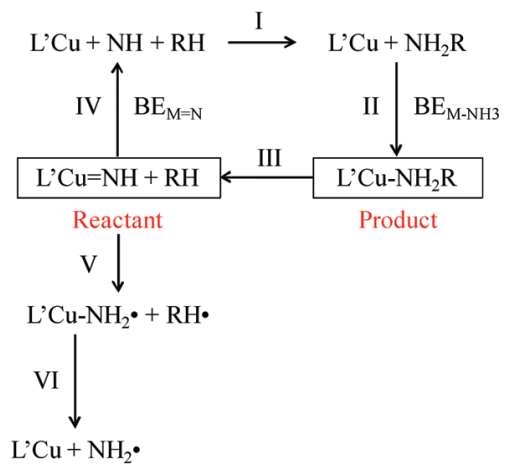

metal accuracy" for the enthalpies of formation of a data set of 17 3d TM complexes. It was suggested by DeYonker and co-workers that "transition metal accuracy" for $\Delta H_{\mathrm{f}}{ }^{\circ}$ is ca. $\pm 3 \mathrm{kcal} \mathrm{mol}^{-1}$ due to the larger experimental uncertainty inherent in the study of such species. ${ }^{41}$ The ccCA methodology employed in this study is outlined by DeYonker et al. ${ }^{41}$ Briefly, the equilibrium geometry, frequency analysis, and zero-point energy (scaled by 0.9890 ) were obtained at the B3LYP/cc-pVTZ level of theory using the Gaussian 03 software package. Separate extrapolation of the HF and correlation energy to the complete basis set (CBS) limit was performed, because, as shown in prior work, the HF energy converges more rapidly to the CBS limit than the correlation energy. ${ }^{41}$ The HF/CBS energy and MP2/CBS correlation energy were then combined to form the "reference energy." A series of contributions were then added to the reference energy, $E(\mathrm{MP} 2 / \mathrm{CBS})$, to account for correlation energy beyond the MP2 level of theory \{estimated at the CCSD(T)/ cc-pVTZ level of theory, $[\Delta E(\mathrm{CC})]\}$, core-valence effects at the MP2 level of theory $[\Delta E(\mathrm{CV})]$, and scalar relativistic effects at the MP2 level of theory $[\Delta E(\mathrm{SR})]$. The zero-point energy (ZPE) corrections were used to account for anharmonicity and were taken from the B3LYP/cc-pVTZ calculations. The ccCA energy is calculated as

$$
\begin{aligned}
E_{\mathrm{ccCA}}=E(\mathrm{MP} 2 / \mathrm{CBS})+\Delta \mathrm{E}(\mathrm{CC})+ & \Delta E(\mathrm{CV})+ \\
& \Delta E(\mathrm{SR})+\mathrm{ZPE}
\end{aligned}
$$

The energies for methane functionalization reactions by $\mathrm{L}^{\prime} \mathrm{Cu}(\mathrm{NMe})$, outlined in Scheme $1\left(\mathrm{H}_{2}\right.$ activation and functionalization by $\mathrm{L}^{\prime} \mathrm{Cu}(\mathrm{NH})$ are analogous) have been calculated using DFT and ccCA methods. In an effort to improve and quantify our understanding of the response of TM reaction mechanisms - thermodynamics and kinetics-to differing levels of theory (in particular, composite ab initio methods), models of important reactions involved in strong bond activation have been studied. Points of particular interest in this research are to compare and contrast (a) the popular B3LYP functional with newer PBE1KCIS and B97-1 functionals and (b) DFT versus ccCA techniques.

For the $\mathrm{L}^{\prime} \mathrm{Cu}(\mathrm{NH})$ active species, a singlet ground state has been predicted by CASSCF; this is an open-shell singlet that single reference methodologies such as DFT and ccCA cannot fully characterize (note that pure functionals such a BLYP and BP86 also predict a triplet ground state for the nitrene complex). Therefore, it is of interest to also inves-

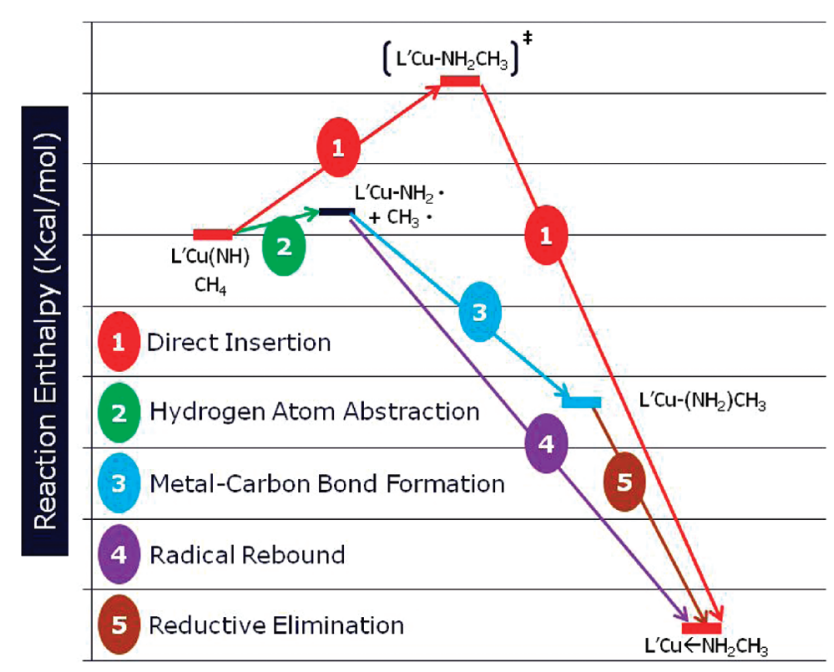

Figure 1. Reaction pathways of $\mathrm{C}-\mathrm{H}$ bond activation of $\mathrm{CH}_{4}$ by $\mathrm{L}^{\prime} \mathrm{Cu}(\mathrm{NH})$. Pathways for $\mathrm{H}_{2}$ activation are analogous. Enthalpy scale is arbitrary.

tigate this important entity with a multireference (MR) equivalent of the ccCA. To create a MR-ccCA methodology, Wilson and co-workers replaced the MP2 calculations within the ccCA method with CASPT2 calculations and the $\operatorname{CCSD}(\mathrm{T})$ calculation of the $E(\mathrm{CC})$ term with an average quadratic coupled cluster (AQCC) calculation. All multireference calculations were performed in the MOLPRO 2006.1 program package. ${ }^{59}$ This formalism has been utilized recently by Mintz et al. to study the potential energy surfaces of $\mathrm{C}_{2}$ and $\mathrm{N}_{2}$ and resulted in good agreement for their reaction coordinates, which are particularly multireference in the vicinity of the dissociation asymptote. ${ }^{60}$ Due to the size of the copper nitrene system and the computational demand of the AQCC calculation, the active space chosen for all MR calculations was four electrons in five orbitals. Previous calculations by Dinescu et al. on copper-nitrene complexes indicated that CASSCF active spaces of this size were suitable for modeling the different low-energy electronic states. $^{29}$

\section{Results and Discussion}

The copper model catalyst, $\mathrm{L}^{\prime} \mathrm{Cu}$, is a closed-shell system with a singlet ground state as supported by DFT calculations by Cundari et al. ${ }^{29}$ The substrates chosen were $\mathrm{H}_{2}$ and $\mathrm{CH}_{4}$ as models for the $\mathrm{H}-\mathrm{H}$ and $\mathrm{C}-\mathrm{H}$ bond activation, respectively. The copper-nitrene active species, $\mathrm{L}^{\prime} \mathrm{Cu}(\mathrm{NH})$ or $\mathrm{L}^{\prime} \mathrm{Cu}(\mathrm{NMe})$, were evaluated in both singlet and triplet spin states. It is worth reiterating that CASSCF calculations of copper-nitrene complexes indicated an "open-shell" singlet ground state, contrary to prior DFT predictions. ${ }^{29}$

1. DFT Calculations. 1.1. Comparison of Different Levels of Theory. Calculated reaction pathways for $\mathrm{H}-\mathrm{H}$ and $\mathrm{C}-\mathrm{H}$ bond activation of methane by $\mathrm{L}^{\prime} \mathrm{Cu}(\mathrm{NH})$ are depicted in Figure 1. The nitrene $\mathrm{L}^{\prime} \mathrm{Cu}(\mathrm{NH})$ can undergo $[1+2]$ insertion to lead directly to a metal-bound amine product (i.e., $\mathrm{L}^{\prime} \mathrm{Cu} \leftarrow \mathrm{NH}_{2} \mathrm{CH}_{3}$ ), shown in Figure 2. Previous experimental and computational research implicate a direct insertion pathway. ${ }^{27,28} \mathrm{We}$ also dissected the direct $[1+2]$ path into HAA of the substrate to produce an amide intermediate 


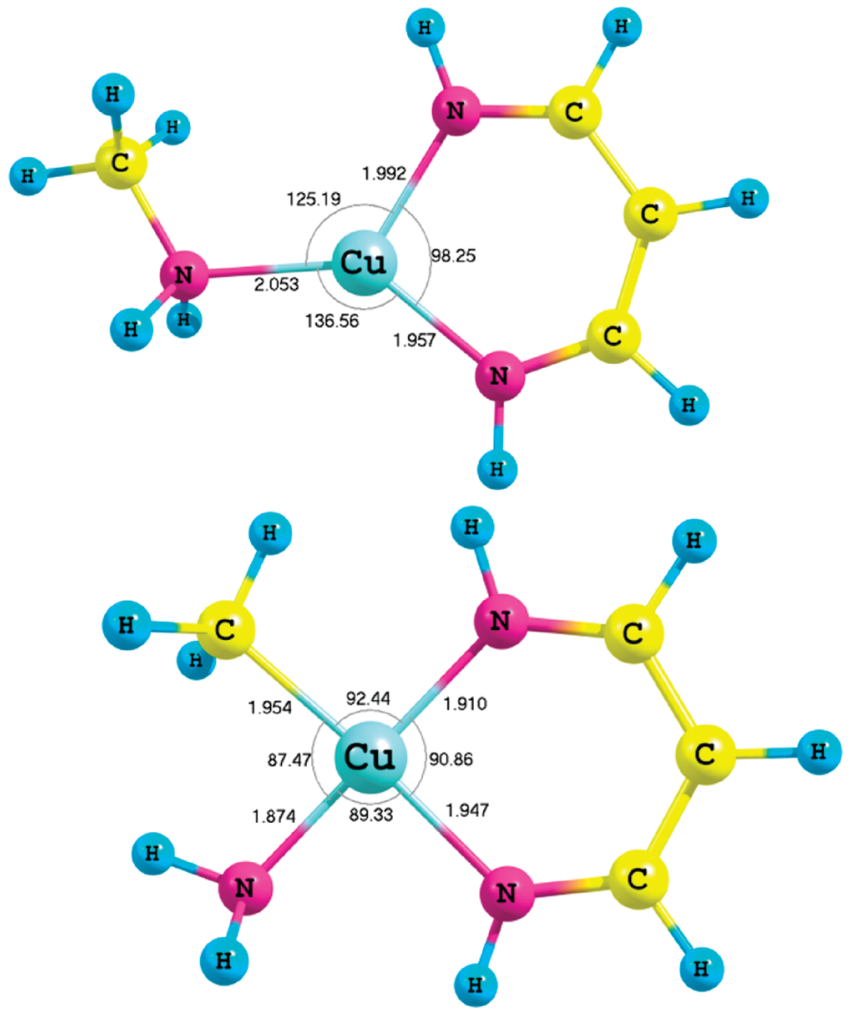

Figure 2. Optimized geometries of $\mathrm{L}^{\prime} \mathrm{Cu} \leftarrow \mathrm{NH}_{2} \mathrm{CH}_{3}$ (top) and $\mathrm{L}^{\prime} \mathrm{CuNH} \mathrm{N}_{2}\left(\mathrm{CH}_{3}\right)$ (bottom) using the B3LYP/6-311++G(d,p) method. The pertinent bond lengths $(\AA)$ and bond angles (deg) are shown.

$\mathrm{L}^{\prime} \mathrm{Cu}-\mathrm{NH}_{2}{ }^{\bullet}$ and a radical $\mathrm{CH}_{3}{ }^{\bullet}$ (or $\mathrm{H}^{*}$ ), which may undergo either (i) metal-carbon bond formation to form (pathway 3 , Figure 2) the four-coordinate complex $\mathrm{L}^{\prime} \mathrm{Cu}\left(\mathrm{NH}_{2}\right) \mathrm{CH}_{3}$ (Figure 2) or (ii) radical rebound to form $\mathrm{L}^{\prime} \mathrm{Cu} \leftarrow \mathrm{NH}_{2} \mathrm{CH}_{3}$ (Figure 2). The methyl(amide) intermediate $\mathrm{L}^{\prime} \mathrm{Cu}\left(\mathrm{NH}_{2}\right) \mathrm{CH}_{3}$ can undergo reductive elimination to produce amine product $\mathrm{L}^{\prime} \mathrm{Cu} \leftarrow \mathrm{NH}_{2} \mathrm{CH}_{3}$. Calculations show pathways similar to those depicted in Figure 1.

There is no significant difference in optimized bond lengths and bond angles for the species investigated (see Scheme 1 and Figure 2) among all three DFT methods evaluated. Therefore, the optimized geometries for all stationary points given in the figures are those determined at the B3LYP/6$311++\mathrm{G}(\mathrm{d}, \mathrm{p})$ level. Figures 3 and 4 show the nitrene active species and $[1+2]$ insertion transition states (for the latter, methane is the substrate) for singlet and triplet multiplicities.

As can be deduced from Table 1, calculated differences among the energetics for the three DFT methods are minimal for hybrid (B3LYP and B97-1) and hybrid meta-GGA (PBE1KCIS) functionals, Pople and correlation consistent basis sets. For $\mathrm{H}_{2}$ reactions, the largest calculated deviation among DFT energetics is $5.9 \mathrm{kcal} \mathrm{mol}^{-1}$, the difference between B3LYP/6-311++G(d,p) and PBE1KCIS/cc-pVTZ enthalpies for reaction III in Scheme 1 on both the singlet and triplet state surfaces. Reaction III is the microscopic reverse of $\mathrm{H}-\mathrm{H}$ bond activation by $\mathrm{L}^{\prime} \mathrm{Cu}(\mathrm{NH})$ to create $\mathrm{L}^{\prime} \mathrm{Cu} \leftarrow \mathrm{NH}_{3}$.

For methane reactions, Scheme 1, the most significant difference is $10.5 \mathrm{kcal} \mathrm{mol}^{-1}$ between PBE1KCIS/cc-pVTZ and B97-1/cc-pVTZ for the calculation of the reaction
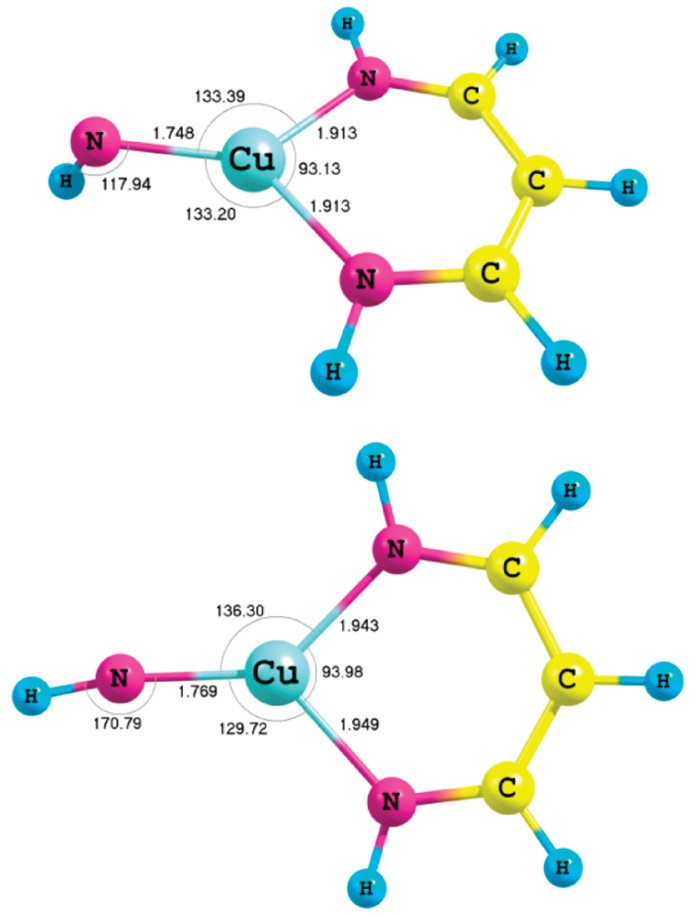

Figure 3. Optimized geometries of the singlet (top) and triplet (bottom), L'Cu(NH) using the B3LYP/6-311++G(d,p) method. The pertinent bond lengths $(\AA)$ and bond angles (deg) are shown.

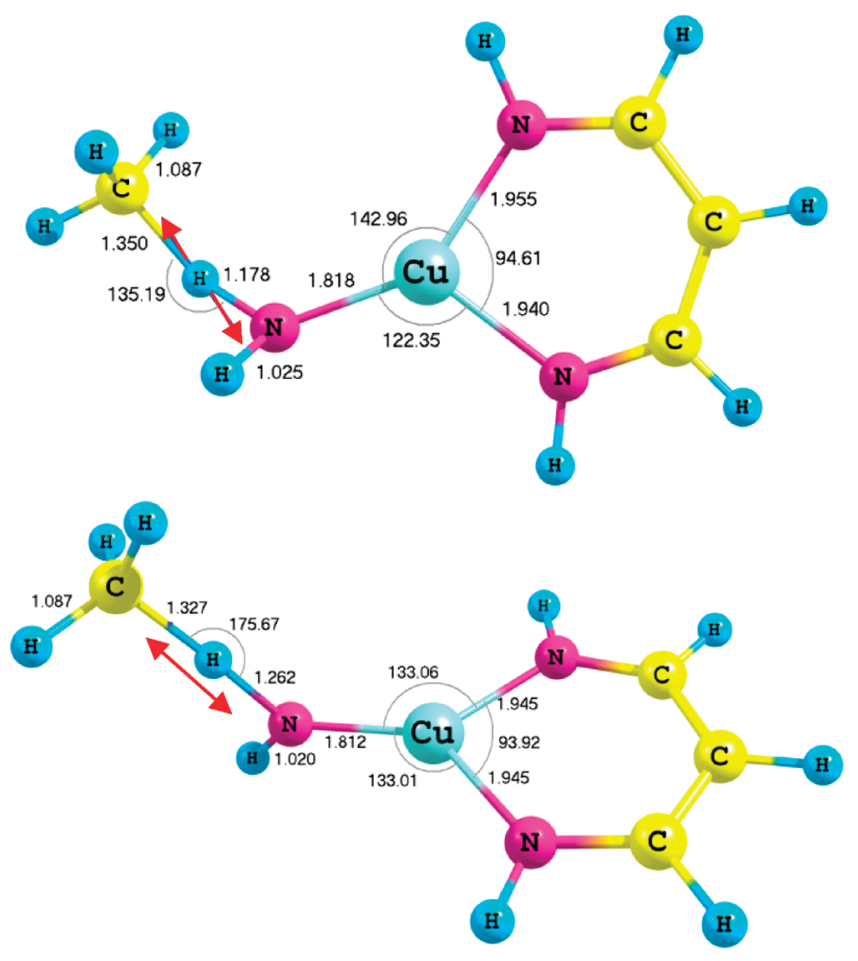

Figure 4. Transition state for direct $\mathrm{C}-\mathrm{H}$ insertion at the $\mathrm{B} 3 \mathrm{LYP} / 6-311++\mathrm{G}(\mathrm{d}, \mathrm{p})$ level of theory. The top geometry is the singlet $\left(v \mathrm{i}=861 \mathrm{i} \mathrm{cm}^{-1}\right)$, while the bottom geometry is the triplet $\left(v \mathrm{i}=1643 \mathrm{i} \mathrm{cm}^{-1}\right)$. The pertinent bond lengths $(\AA)$ and bond angles (deg) are shown.

barrier height (i.e., $\mathrm{R} \rightarrow \mathrm{TS}$ ) on the triplet surface. While sensitivity of transition states and hence reaction barriers to the level of theory is perhaps expected, what is more surprising are the differences in the ground state energetics. 
Table 1. $\Delta H$ in $\mathrm{kcal} \mathrm{mol}^{-1}$ for All Reactions Shown in Scheme $1^{a}$

\begin{tabular}{|c|c|c|c|c|c|c|c|c|}
\hline \multirow[b]{3}{*}{ method } & \multicolumn{8}{|c|}{$\mathrm{H}-\mathrm{H}$ Activation Results } \\
\hline & \multicolumn{4}{|c|}{ singlet state $(S=0)$ calculation results } & \multicolumn{4}{|c|}{ triplet state $(S=1)$ calculation results } \\
\hline & B3LYP & PBE1KCIS & B97-1 & & B3LYP & PBE1KCIS & B97-1 & \\
\hline$R \rightarrow P$ & -83.9 & -89.7 & -84.9 & -72.5 & -70.5 & -76.4 & -72.1 & -76.1 \\
\hline $\mathrm{R} \rightarrow \mathrm{TS}$ & 3.4 & 0.7 & 2.4 & 5.9 & 8.9 & 6.0 & 7.7 & 27.3 \\
\hline $\mathrm{TS} \rightarrow \mathrm{P}$ & -87.3 & -90.4 & -87.3 & -78.4 & -79.3 & -82.4 & -79.8 & -103.5 \\
\hline III & 83.9 & 89.7 & 84.9 & 72.5 & 70.5 & 76.4 & 72.1 & 76.1 \\
\hline IV & 25.5 & 27.6 & 28.7 & 42.6 & 38.9 & 40.9 & 41.5 & 38.9 \\
\hline V & -9.6 & -14.7 & -13.6 & 19.0 & 3.8 & -1.4 & -0.8 & 15.3 \\
\hline VI & 47.0 & 49.4 & 50.0 & 34.5 & 47.0 & 49.4 & 50.0 & 34.5 \\
\hline
\end{tabular}

C-H Activation Results

\begin{tabular}{|c|c|c|c|c|c|c|c|c|}
\hline \multirow[b]{2}{*}{ method } & \multicolumn{4}{|c|}{ singlet state $(S=0)$ calculation results } & \multicolumn{4}{|c|}{ triplet state $(S=1)$ calculation results } \\
\hline & B3LYP & PBE1KCIS & B97-1 & & B3LYP & PBE1KCIS & B97-1 & \\
\hline basis set & $6-311++G(d, p)$ & cc-pVTZ & cc-pVTZ & $\operatorname{ccCA}$ & $6-311++G(d, p)$ & cc-pVTZ & cc-pVTZ & $\operatorname{ccCA}$ \\
\hline $\mathrm{R} \rightarrow \mathrm{TS}$ & 7.3 & 4.8 & 5.9 & 12.7 & 13.1 & 10.2 & 18.8 & 29.7 \\
\hline $\mathrm{TS} \rightarrow \mathrm{P}$ & -67.8 & -69.8 & -68.0 & -63.7 & -59.6 & -61.8 & -59.3 & -84.4 \\
\hline I & 10.9 & 9.7 & 11.0 & 11.5 & 10.9 & 9.7 & 11.0 & 11.5 \\
\hline IV & 25.5 & 27.6 & 28.7 & 42.6 & 39.5 & 40.9 & 41.5 & 38.9 \\
\hline V & -11.0 & -11.8 & -9.6 & 19.5 & 3.0 & 1.5 & 3.2 & 15.8 \\
\hline VI & 47.0 & 49.4 & 50.0 & 34.5 & 47.0 & 49.4 & 50.0 & 34.5 \\
\hline
\end{tabular}

${ }^{a} \mathrm{R}, \mathrm{TS}$, and $\mathrm{P}$ denote the reactant, transition state, and product, respectively.

More specifically, there are cases where the absolute value of the deviation among the three DFT methods is 10.4 (B3LYP/6-311++G(d,p) versus PBE1KCIS/cc-pVTZ) and 10.1 (B3LYP/6-311++G(d,p) vs B97-1/cc-pVTZ) kcal $\mathrm{mol}^{-1}$ in the $\mathrm{C}-\mathrm{H}$ bond activation reaction coordinates. Both of these results are for reaction II in Scheme 1, which is the binding enthalpy of methyl amine to the $\beta$-diketiminate- $\mathrm{Cu}$ complex. The sensitivity of reaction II is noteworthy given that it entails the coordination of a closed-shell Lewis base (ammonia) to a closed-shell Lewis acid $\left(\mathrm{L}^{\prime} \mathrm{Cu}\right)$. The average difference as quantified by the mean absolute deviation (MAD) among the three DFT methods is generally small (1.6-5.4 $\mathrm{kcal} \mathrm{mol}^{-1}$ ) with the exception of the reactions mentioned above. In section 2, we will compare ccCA predicted energetics to those obtained with density functional theory.

1.2. The Ground State of Copper Nitrene $\left[L^{\prime} \mathrm{Cu}(\mathrm{NH})\right]$. DFT calculations on $\mathrm{L}^{\prime} \mathrm{Cu}(\mathrm{NH})$, Figure 3, predict that the triplet state is lower than the singlet state for all three levels of theory evaluated here: B3LYP/6-311+G(d,p), PBE1KCIS/ cc-pVTZ, and B97-1/cc-pVTZ. The difference between the triplet and singlet states is nearly identical for each functional, 13.4, 13.3, and $12.9 \mathrm{kcal} \mathrm{mol}^{-1}$, respectively, similar to DFT values reported previously by Cundari et al. ${ }^{29}$ However, previous multireference calculations indicated the ground state of copper( $\beta$-diketiminate)(nitrene) complexes to be a singlet. ${ }^{29}$ The singlet state of $\mathrm{L}^{\prime} \mathrm{Cu}(\mathrm{NH})$ is thus best described with methods that can incorporate the multireference character of this open-shell singlet. DFT is, of course, a single determinant modeling technique. ${ }^{61} \mathrm{We}$ will revisit the singlet-triplet splitting of $\mathrm{L}^{\prime} \mathrm{Cu}(\mathrm{NH})$ with ab initio techniques in the following section.

2. ccCA Calculations. In light of the prediction of the singlet-triplet splitting of $\mathrm{L}^{\prime} \mathrm{Cu}(\mathrm{NH})$ by different DFT methods, in comparison to previous CASSCF calculations, ${ }^{29}$ it is of interest to evaluate the predictions of wave functionbased approaches such as ccCA. These calculations were performed at the B3LYP/cc-pVTZ optimized geometries given the similarity in geometry among the different functional/basis set combinations. The ccCA method predicts that the singlet state of $L^{\prime} \mathrm{Cu}(\mathrm{NH})$ is lower than the triplet state by $3.7 \mathrm{kcal} \mathrm{mol}^{-1}$, which is comparable in magnitude and direction with the predictions made via CASSCF calculations $\left(5.6 \mathrm{kcal} \mathrm{mol}^{-1}\right){ }^{29}$ Since there is similarity among the DFT methods vis-à-vis the difference in energy between ${ }^{1,3} \mathrm{~L}^{\prime} \mathrm{Cu}(\mathrm{NH})$, the deviation between ccCA and all three DFT predictions of the singlet-triplet splitting is very similar, that is, a difference of $\sim 17 \mathrm{kcal} \mathrm{mol}^{-1}$ and with a reversal of ordering of the two multiplicities.

2.1. ccCA Prediction of Copper Nitrene Ground State. A breakdown of the ccCA energy into its components is very interesting in terms of how each constituent "prefers" either the singlet or triplet state of $\mathrm{L}^{\prime} \mathrm{Cu}(\mathrm{NH})$ as the ground state. Table 2 shows ccCA reference energy [ $E(\mathrm{MP} 2 / \mathrm{CBS})$ in eq 1] and the breakdown of each contributing term to the total ccCA energy. Note that similar comments can be made for the singlet - triplet ordering of the transition states for $\mathrm{C}-\mathrm{H}$ and $\mathrm{H}-\mathrm{H}$ insertion, Table 2. The ccCA reference energy predicts that the singlet state is lower than the triplet state for the $\mathrm{L}^{\prime} \mathrm{Cu}(\mathrm{NH})$ active species by $14.9 \mathrm{kcal} \mathrm{mol}^{-1}$. When 
Table 2. Correlation Consistent Composite Approach (ccCA) Total Energy at $298 \mathrm{~K}$ and the Constituent Terms in au for Complexes at the Singlet and Triplet States

\begin{tabular}{|c|c|c|c|c|c|c|c|}
\hline complex & electronic state & $\begin{array}{c}\text { ccCA reference } \\
\text { energy }^{a}\end{array}$ & correlation effects term & $\begin{array}{c}\text { core valence } \\
\text { term }\end{array}$ & $\begin{array}{c}\text { relativistic effects } \\
\text { term }\end{array}$ & $\begin{array}{l}\text { zero-point } \\
\text { correction }\end{array}$ & $\begin{array}{c}\text { ccCA total } \\
\text { energy at } 298 \mathrm{~K}\end{array}$ \\
\hline $\begin{array}{l}\mathrm{L}^{\prime} \mathrm{Cu}-\mathrm{NH} \\
\mathrm{L}^{\prime} \mathrm{Cu}-\mathrm{NH} \\
\mathrm{L}^{\prime} \mathrm{Cu}-\mathrm{NH}_{3}(\mathrm{TS})^{b} \\
\mathrm{~L}^{\prime} \mathrm{Cu}-\mathrm{NH}_{3}(\mathrm{TS}) \\
\mathrm{L}^{\prime} \mathrm{Cu}-\mathrm{NH}_{2} \mathrm{CH}_{3}(\mathrm{TS}) \\
\mathrm{L}^{\prime} \mathrm{Cu}-\mathrm{NH}_{2} \mathrm{CH}_{3}(\mathrm{TS})\end{array}$ & $\begin{array}{l}\text { singlet } \\
\text { triplet } \\
\text { singlet } \\
\text { triplet } \\
\text { singlet } \\
\text { triplet }\end{array}$ & $\begin{array}{l}-1921.315616 \\
-1921.291884 \\
-1922.461932 \\
-1922.391377 \\
-1961.714306 \\
-1961.652950\end{array}$ & $\begin{array}{l}-0.019974 \\
-0.040519 \\
-0.038028 \\
-0.094062 \\
-0.062155 \\
-0.112235\end{array}$ & $\begin{array}{l}-0.807883 \\
-0.806430 \\
-0.809139 \\
-0.785643 \\
-0.856912 \\
-0.834112\end{array}$ & $\begin{array}{l}-14.309706 \\
-14.307726 \\
-14.310405 \\
-14.305786 \\
-14.321781 \\
-14.320529\end{array}$ & $\begin{array}{l}0.104388 \\
0.103626 \\
0.118110 \\
0.115420 \\
0.150333 \\
0.148067\end{array}$ & $\begin{array}{l}-1936.348792 \\
-1936.342932 \\
-1937.501394 \\
-1937.461448 \\
-1976.804821 \\
-1976.771758\end{array}$ \\
\hline
\end{tabular}

${ }^{a}$ Reference energy is computed from the Schwartz two-point extrapolation equation of the MP2 energies at the aug-cc-pVTZ and aug-cc-pVQZ basis sets. ${ }^{b}$ TS refers to the energy of complex at the transition state.

Table 3. Multireference Correlation Consistent Composite Approach (MR-ccCA) Total Energy and the Constituent Terms in au for Complexes at the Singlet and Triplet State

\begin{tabular}{|c|c|c|c|c|c|c|c|}
\hline complex & electronic state & MR-ccCA reference energy ${ }^{a}$ & $\begin{array}{l}\text { correlation } \\
\text { effects term }\end{array}$ & $\begin{array}{l}\text { core valence } \\
\text { term }\end{array}$ & $\begin{array}{l}\text { relativistic } \\
\text { effects term }\end{array}$ & $\begin{array}{l}\text { zero-point } \\
\text { correction }\end{array}$ & $\begin{array}{l}\text { MR-ccCA total } \\
\text { energy at } 298 \mathrm{~K}\end{array}$ \\
\hline $\begin{array}{l}\mathrm{L}^{\prime} \mathrm{Cu}-\mathrm{NH} \\
\mathrm{L}^{\prime} \mathrm{Cu}-\mathrm{NH}\end{array}$ & $\begin{array}{l}\text { singlet } \\
\text { triplet }\end{array}$ & $\begin{array}{l}-1921.176380 \\
-1921.152392\end{array}$ & $\begin{array}{l}0.043125 \\
0.031002\end{array}$ & $\begin{array}{l}-0.760333 \\
-0.760049\end{array}$ & $\begin{array}{l}-14.308796 \\
-14.305705\end{array}$ & $\begin{array}{l}0.104388 \\
0.103626\end{array}$ & $\begin{array}{l}-1936.097995 \\
-1936.083518\end{array}$ \\
\hline
\end{tabular}

\footnotetext{
${ }^{a}$ Reference energy is computed from the Schwartz two-point extrapolation equation of the CASPT2 energies with the aug-cc-pVDZ and
} aug-cc-pVTZ basis sets for $\mathrm{L}^{\prime} \mathrm{Cu}-\mathrm{NH}$.

electron correlation $[\triangle E(C C)]$ is added beyond the MP2 level, the singlet and triplet state of $\mathrm{L}^{\prime} \mathrm{Cu}(\mathrm{NH})$ now display a difference of $2.0 \mathrm{kcal} \mathrm{mol}^{-1}$, with the singlet still lower in energy. The coupled cluster calculation thus counteracts, but does not reverse, the MP2-based reference energy, leaving $\mathrm{L}^{\prime} \mathrm{Cu}(\mathrm{NH})$ in a close energetic balance among the two spin states. The other additive terms (core-valence, relativistic, and zero-point energy) have negligible difference, although the difference in core-valence contributions is more significant for the transition states than the ground state $\mathrm{L}^{\prime} \mathrm{Cu}(\mathrm{NH})$, Table 2 . The core-valence correction favors the singlet state and may be a reflection of the change in formal oxidation state at copper.

2.2. Multireference ccCA (MR-ccCA) Prediction of Copper Nitrene Ground State. As shown in Table 3, MRccCA supports previous CASSCF and single-reference ccCA calculations, that is, that a singlet is the electronic ground state of the copper nitrene, $\mathrm{L}^{\prime} \mathrm{Cu}(\mathrm{NH})$. In the case of MRccCA, the singlet state is predicted to be $9.1 \mathrm{kcal} \mathrm{mol}^{-1}$ lower in energy than the triplet state. Interestingly, this value is approximately halfway between DFT and single reference ccCA predictions. Furthermore, we note that all of the MR component calculations in MR-ccCA predict that the singlet state is the lower energy than the triplet state, Table 3; although, similar to single reference ccCA, adding in electron correlation beyond second-order perturbation theory acts to reduce the singlet-triplet splitting of $\mathrm{L}^{\prime} \mathrm{Cu}(\mathrm{NH})$. As a final justification for the use of MR-ccCA, the leading reference coefficients predicted with the AQCC method for both the singlet and triplet system are 0.722 and 0.814 , respectively, indicating significant multireference character.

2.3. Reaction Coordinates: Comparison of ccCA versus $D F T$. Since the reaction energy differences among the three DFT methods are similar for the majority of the component reactions, Scheme 1 and Figure 2, we focus on B3LYP/6$311++\mathrm{G}(\mathrm{d}, \mathrm{p})$ and ccCA results for the remaining discussion. Comparing the $\mathrm{H}-\mathrm{H}$ bond activation reaction coordinates (singlet state), we find that the largest B3LYP-ccCA difference is $28.6 \mathrm{kcal} \mathrm{mol}^{-1}$ for reaction $\mathrm{V}$, which involves the multireference molecule, $\mathrm{L}^{\prime} \mathrm{Cu}(\mathrm{NH})$ : the HAA reaction of $\mathrm{L}^{\prime} \mathrm{Cu}(\mathrm{NH})$ with $\mathrm{H}_{2}$ to yield $\mathrm{L}^{\prime} \mathrm{Cu}\left(\mathrm{NH}_{2}\right)$ and $\mathrm{H}$ atom. The lowest difference is $0 \mathrm{kcal} \mathrm{mol}^{-1}$ for reaction IV, the dissociation of imidogen $\left({ }^{3} \mathrm{NH}\right)$ from the triplet copper-nitrene complex to yield the copper catalyst model, $\mathrm{L}^{\prime} \mathrm{Cu}$ (i.e., there was essentially no difference between ccCA and B3LYP for reaction IV). Comparing the triplet potential energy surface for $\mathrm{H}-\mathrm{H}$ bond activation, we found that the largest DFTccCA calculated difference is $12.5 \mathrm{kcal} \mathrm{mol}^{-1}$ for reaction VI, which described the bond dissociation energy of the copper-nitrogen bond of $\mathrm{L}^{\prime} \mathrm{Cu}\left(\mathrm{NH}_{2}\right)$. Thus, in general, it appears that the biggest divergence between the DFT and ccCA methods is for those processes that involve radical species and homoloytic bond dissociation.

There are two plausible reaction mechanisms for $\mathrm{C}-\mathrm{H}$ and $\mathrm{H}-\mathrm{H}$ bond activation by a copper-nitrene complex: a concerted $[1+2]$ direct insertion and nonconcerted pathways initiated by HAA reaction. Previous DFT calculations in concert with experimental studies support a mechanism involving direct $[1+2]$ insertion. ${ }^{30}$ On the singlet surface for $\mathrm{H}_{2}$ functionalization, the $[1+2]$ insertion reaction is calculated to be exothermic by $-72.5 \mathrm{kcal} \mathrm{mol}^{-1}$ versus $-83.9 \mathrm{kcal} \mathrm{mol}^{-1}$ determined at the B3LYP/6-311++G(d,p) level of theory, Table 1 . The singlet insertion barrier is small using both density functional and wave function based techniques $\left(3.4 \mathrm{kcal} \mathrm{mol}^{-1}\right.$ for B3LYP/6-311++G(d,p) and $5.9 \mathrm{kcal} \mathrm{mol}^{-1}$ for ccCA). The kinetic barrier to $\mathrm{H}_{2}$ insertion is more divergent on the triplet surface: $8.9 \mathrm{kcal} \mathrm{mol}^{-1}$ for B3LYP/6-311++G(d,p) and $27.3 \mathrm{kcal} \mathrm{mol}^{-1}$ for ccCA. For the methane functionalization pathway, Table 1, there is more congruity between DFT- and ccCA-calculated energetics, although as for the $\mathrm{H}_{2}$ reactions, discrepancies are more apparent on the triplet than the singlet surface.

\section{Summary and Conclusions}

The kinetics and thermodynamics of nitrene insertion into $\mathrm{C}-\mathrm{H}$ and $\mathrm{H}-\mathrm{H}$ have been studied using several levels of theory: B3LYP/6-311++G(d,p), B97-1/cc-pVTZ, PBE1KCIS/ 
cc-pVTZ, and ccCA. Each DFT method shows no significant difference from the other two DFT methods despite the use of both hybrid and meta-GGA functionals, as well as both Pople-style and correlation consistent basis sets. Hence, the deviations of ccCA results with respect to the different DFT methods studied here are very similar. All three DFT methods predict the ground state of $\mathrm{L}^{\prime} \mathrm{Cu}(\mathrm{NH})$ to be the triplet; however, ccCA results show the singlet state to be the ground state. The contributions to the total ccCA energy indicate that ccCA prediction of the singlet state is due to ccCA reference energy. The ccCA reference energy (which mimics the complete basis set limit of MP2) predicts that the singlet state is lower than the triplet state for the $\mathrm{L}^{\prime} \mathrm{Cu}(\mathrm{NH})$ active species by $14.9 \mathrm{kcal} \mathrm{mol}^{-1}$. When electron correlation $[\Delta E(\mathrm{CC})]$ is added beyond the MP2 level, the singlet and triplet state of $\mathrm{L}^{\prime} \mathrm{Cu}(\mathrm{NH})$ display a difference of $2.0 \mathrm{kcal}$ $\mathrm{mol}^{-1}$, with the singlet still lower in energy. The coupled cluster calculation thus counteracts, but does not reverse, the MP2-based reference energy, leaving $\mathrm{L}^{\prime} \mathrm{Cu}(\mathrm{NH})$ in a close energetic balance among the two spin states. MR-ccCA calculations are in agreement with CASSCF and single reference ccCA and yield a singlet-triplet splitting of 8.3 $\mathrm{kcal} \mathrm{mol}^{-1}$, which is halfway between the DFT and singlereference ccCA predictions. In general, the largest difference between DFT and ccCA methods is for those processes that involve radical species and homoloytic bond dissociation. Other research in our group indicates that spin contamination can be problematic in open-shell organic ${ }^{62}$ and inorganic compounds, ${ }^{63}$ making the use of restricted open-shell methodologies a prudent choice. However, no evidence for spin contamination was seen in the present research.

Acknowledgment. This research was supported in part by a grant from the National Science Foundation (CHE0701247) to T.R.C. Calculations employed the UNT computational chemistry resource, for which T.R.C. acknowledges the NSF for support through CRIF grant CHE0741936.

Supporting Information Available: Tables of total energies and enthalpies of all complexes in au. Animated graphics files for the calculated TSs are also available. This material is available free of charge via the Internet at http:// pubs.acs.org.

\section{References}

(1) Fairlamb, I. J. S. Annu. Rep. Prog. Chem. B 2006, 102, 50.

(2) Fekl, U.; Goldberg, K. I. Adv. Inorg. Chem. 2003, 54, 259.

(3) Goj, L. A.; Gunnoe, B. T. Curr. Org. Chem. 2005, 9, 671.

(4) Labinger, J. A.; Bercaw, J. E. Nature 2002, 417, 507.

(5) Lersch, M.; Tilset, M. Chem. Rev. 2005, 105, 247.

(6) Cenini, S.; Gallo, E.; Caselli, A.; Ragaini, F.; Fantauzzi, S.; Piangiolino, C. Coord. Chem. Rev. 2006, 250, 1234.

(7) Ittel, S. D.; Johnson, J. K.; Brookhart, M. Chem. Rev. 2000, 100, 1169.

(8) Kitiachvili, K. D.; Mindiola, D. J.; Hillhouse, G. L. J. Am. Chem. Soc. 2004, 126, 10554.

(9) Melenkivitz, R.; Mindiola, D. J.; Hillhouse, G. L. J. Am. Chem. Soc. 2002, 124, 3846.
(10) Mindiola, D. J.; Hillhouse, G. L. Chem. Comm. 2002, 17, 1840.

(11) Mindiola, D. J.; Hillhouse, G. L. J. Am. Chem. Soc. 2002, 124, 9976.

(12) Miniola, D. J.; Hillhouse, G. L. J. Am. Chem. Soc. 2001, $123,4623$.

(13) Waterman, R.; Hillhouse, G. L. Organometallics 2002, 23, 5182.

(14) Waterman, R.; Hillhouse, G. L. J. Am. Chem. Soc. 2003, $125,13350$.

(15) Bourget-Merle, L.; Lappert, M. F.; Severn, J. R. Chem. Rev. 2002, 102, 3031.

(16) Shimokawa, C.; Yokota, S.; Tachi, Y.; Nishiwaki, N.; Ariga, M.; Itoh, S. Inorg. Chem. 2003, 42, 8395. See also: Hong, S.; Hill, L. M. R.; Gupta, A. K.; Naab, B. D.; Gilroy, J. B.; Hicks, R. G.; Cramer, C. J.; Tolman, W. B. Inorg. Chem. 2009, 48, 4514.

(17) Eckert, N. A.; Vaddadi, S.; Stoian, S.; Lachicotte, R. J.; Cundari, T. R.; Holland, P. L. Angew. Chem., Int. Ed. 2006, $45,6868$.

(18) Dai, X.; Kapoor, P.; Warren, T. H. J. Am. Chem. Soc. 2003, $126,4798$.

(19) Kogut, E.; Wiencko, H. L.; Zhang, L.; Cordeau, D. E.; Warren, T. H. J. Am. Chem. Soc. 2005, 127, 11248. Baik and coworkers have studied structural transformations in threecoordinate b-diketiminate complexes of chromium:Fan, H.; Adhikari, D.; Saleh, A. A.; Clark, R. L.; Zuno-Cruz, F. J.; Cabrera, G. S.; Huffman, J. C.; Pink, M.; Mindiola, D. J.; Baik, M. J. Am. Chem. Soc. 2008, 130, 17351.

(20) Gillespie, K. M.; Crust, E. J.; Deeth, R. J.; Scott, P. Chem. Commun. 2001, 785.

(21) Diaz-Requejo, M. M.; Belderrain, T. R.; Nicasio, M. C.; Trofimenko, S.; Perez, P. J. J. Am. Chem. Soc. 2003, 125, 12079.

(22) Li, Z.; Capretto, D. A.; Rahaman, R.; He, C. Angew. Chem., Int. Ed. 2007, 46, 5184.

(23) Li, Z.; Capretto, D. A.; Rahaman, R. O.; He, C. J. Am. Chem. Soc. 2007, 129, 12058.

(24) Lovely, C. J.; Browning, R. G.; Polach, S. A.; Dias, H. V. R. Carbene and Nitrene Transfer Reactions Catalyzed by Fluorinated Tris(Pyrazolyl)Borato Copper(I) and Silver(I) Complexes; Abstracts of Papers, 225th ACS National Meeting, New Orleans, LA, March 23-27, 2003, ORGN-032.

(25) Perez, J.; Morales, D.; Garcia-Escudero, L. A.; MartinezGarcía, H.; Miguelb, D.; Bernada, P. Dalton Trans. 2009, 375.

(26) Cano, I.; Nicasio, M. C.; Perez, P. J. Dalton Trans. 2009, 730.

(27) Badiei, Y. M.; Warren, T. H. J. Organomet. Chem. 2005, 690, 5989.

(28) Badiei, Y. M.; Krishnaswamy, A.; Melzer, M. M.; Warren, T. H. J. Am. Chem. Soc. 2006, 128, 15056.

(29) Cundari, T. R.; Dinescu, A.; Kazi, A. B. Inorg. Chem. 2008, 47, 10067.

(30) Badiei, Y. M.; Dinescu, A.; Dai, X.; Palomino, R. M.; Heinemann, F. W.; Cundari, T. R.; Warren, T. H. Angew. Chem., Int. Ed. 2008, 47, 9961.

(31) Periana, R. A.; Taube, D. J.; Gamble, S.; Taube, H.; Satoh, T.; Fuji, H. Science 1998, 280, 560 . 
(32) Periana, R. A.; Taube, D. J.; Evitt, E. R.; Loffler, D. G.; Wentrcek, P. R.; Voss, G.; Masuda, T. Science 1993, 253, 340 .

(33) Jones, C. J.; Taube, D. J.; Ziatdinov, V. R.; Periana, R. A.; Nielsen, R. J.; Oxgaard, J.; Goddard, W. A., III. Angew. Chem., Int. Ed. 2004, 43, 4626.

(34) Xu, X.; Fu, G.; Goddard, W. A., III.; Periana, R. A. Stud. Surf. Sci. Catal. 2004, 147, 499.

(35) Periana, R. A.; Ortmann, D. A.; Mironov, O. A. Mechanistic Aspects of the High-Yield, Methane to Methanol Catalytic System; Abstracts of Papers, 224th ACS National Meeting, Boston, MA, August 18-22, 2002, INOR-465.

(36) Kua, J.; Xu, X.; Periana, R. A.; Goddard, W. A., III. Organometallics 2002, 21, 511.

(37) Periana, R. A.; Ortmann, D. A. Experimental and Theoretical Study of a High-Yield, Methane Hydroxylation Catalyst; Abstracts of Papers, 223rd ACS National Meeting, Orlando, FL, April 7-11, 2002, INOR-157.

(38) Webster, C. E.; Fan, Y.; Hall, M. B.; Kunz, D.; Hartwig, J. F. J. Am. Chem. Soc. 2003, 125, 858

(39) Ho, D. S.; DeYonker, N. J.; Wilson, A. K.; Cundari, T. R. J. Phys. Chem. A 2006, 110, 9767.

(40) DeYonker, N. J.; Mintz, B.; Cundari, T. R.; Wilson, A. K. J. Chem. Theory Comput. 2008, 4, 328.

(41) DeYonker, N. J.; Peterson, K. A.; Steyl, G.; Wilson, A. K.; Cundari, T. R. J. Phys. Chem. 2007, 111, 11269.

(42) Grimes, T. V.; Wilson, A. K.; DeYonker, N. J.; Cundari, T. R. J. Chem. Phys. 2007, 127, 154117.

(43) DeYonker, N. J.; Grimes, T.; Yockel, S.; Dinescu, A.; Mintz, B.; Cundari, T. R.; Wilson, A. K. J. Chem. Phys. 2006, 125, 104111/1.

(44) Frisch, M. J.; Trucks, G. W.; Schlegel, H. B.; Scuseria, G. E.; Robb, M. A.; Cheeseman, J. R.; Montgomery, J. A., Jr.; Vreven, T.; Kudin, K. N.; Burant, J. C.; Millam, J. M.; Iyengar, S. S.; Tomasi, J.; Barone, V.; Mennucci, B.; Cossi, M.; Scalmani, G.; Rega, N.; Petersson, G. A.; Nakatsuji, H.; Hada, M.; Ehara, M.; Toyota, K.; Fukuda, R.; Hasegawa, J.; Ishida, M.; Nakajima, T.; Honda, Y.; Kitao, O.; Nakai, H.; Klene, M.; Li, X.; Knox, J. E.; Hratchian, H. P.; Cross, J. B.; Bakken, V.; Adamo, C.; Jaramillo, J.; Gomperts, R.; Stratmann, R. E.; Yazyev, O.; Austin, A. J.; Cammi, R.; Pomelli, C.; Ochterski, J. W.; Ayala, P. Y.; Morokuma, K.; Voth, G. A.; Salvador, P.; Dannenberg, J. J.; Zakrzewski, V. G.; Dapprich, S.; Daniels, A. D.; Strain, M. C.; Farkas, O.; Malick, D. K.; Rabuck, A. D.; Raghavachari, K.; Foresman, J. B.; Ortiz, J. V.; Cui, Q.; Baboul, A. G.; Clifford, S.; Cioslowski, J.; Stefanov, B. B.; Liu, G.; Liashenko, A.; Piskorz, P.; Komaromi, I.; Martin, R. L.; Fox, D. J.; Keith, T.; Al-Laham, M. A.; Peng, C. Y.; Nanayakkara, A.; Challacombe, M.; Gill, P. M. W.; Johnson, B.; Chen, W.; Wong, M. W.; Gonzalez, C.; Pople,
J. A. Gaussian03, revision D.02; Gaussian, Inc.: Wallingford, CT, 2004.

(45) Stephens, P. J.; Devlin, F. J.; Chabalowski, C. F.; Frisch, M. J. J. Phys. Chem. 1994, 98, 11623.

(46) Dunning, T. H., Jr.; Peterson, K. A.; Wilson, A. K. J. Chem. Phys. 2001, 114, 9244.

(47) Kendall, R. A.; Dunning, T. H., Jr.; Harrison, R. J. J. Chem. Phys. 1992, 96, 6796.

(48) Peterson, K. A.; Dunning, T. H., Jr. J. Chem. Phys. 2002, 117, 10548.

(49) Dunning, T. H., Jr. J. Chem. Phys. 1989, 90, 1007.

(50) Van Mourik, T.; Dunning, T. H., Jr. Int. J. Quantum Chem. 2000, 76, 205.

(51) Wilson, A. K.; Van Mourik, T.; Dunning, T. H., Jr. THEOCHEM 1996, 388, 339.

(52) Wilson, A. K.; Woon, D. E.; Peterson, K. A.; Dunning, T. H., Jr. J. Chem. Phys. 1999, 110, 7667.

(53) Woon, D. E.; Dunning, T. H., Jr. J. Chem. Phys. 1993, 98, 1358.

(54) Woon, D. E.; Dunning, T. H., Jr. J. Chem. Phys. 1995, 103, 4572 .

(55) Becke, A. D. Phys. Rev. A 1988, 38, 3098.

(56) Lee, C.; Yang, W.; Parr, R. G. Phys. Rev. B 1988, 37, 785.

(57) Tekarli, S. M.; Drummond, M. L.; Williams, T. G.; Cundari, T. R.; Wilson, A. K. J. Phys. Chem. A 2009, 113, 8607.

(58) Zhao, Y.; González-García, N.; Truhlar, D. G. J. Phys. Chem. A 2005, 109, 2012.

(59) Werner, H. J.; Knowles, P. J.; Lindh, R.; Manby, F. R.; Schütz, M.; Celani, P.; Korona, T.; Rauhut, G.; Amos, R. D.; Bernhardsson, A.; Berning, A.; Cooper, D. L.; Deegan, J. O.; Dobbyn, A. J.; Eckert, F.; Hampel, C.; Hetzer, G.; Lloyd, A. W.; McNicholas, S. J.; Meyer, W.; Mura, M. E.; Nicklass, A.; Palmieri, P.; Pitzer, R.; Schumann, U.; Stoll, H.; Stone, A. J.; Tarroni, R.; Thorsteinsson, T. MOLPRO, version 2006.1; University College Cardiff Consultants Limited: Cardiff, South Glamorgan, U. K., 2006.

(60) Mintz, B.; Williams, T. G.; Howard, L.; Wilson, A. K. J. Chem. Phys. 2009, 130, 234104/1.

(61) Schultz, N. E.; Zhao, Y.; Truhlar, D. G. J. Phys. Chem. A. 2005, 109, 11127.

(62) Gao, Y.; DeYonker, N. J.; Garrett, E. C.; Wilson, A. K.; Cundari, T. R.; Marshall, P. J Phys. Chem. A 2009, 113, 6955.

(63) DeYonker, N. J.; Williams, T. G.; Imel, A. E.; Cundari, T. R.; Wilson, A. K. J. Chem. Phys. 2009, 131, 024106/1.

CT900277M 